\title{
Optimising endoscopic management of early gastrointestinal neoplasia
}

Tiing Leong Ang, FRCPEd, FAMS

n $\mathrm{n}$ this issue of the Singapore Medical Journal, Koay et $\mathrm{al}^{(1)}$ examined the role of narrow-band imaging (NBI), an image-enhanced endoscopy (IEE) technique, for the diagnosis of duodenal villous atrophy, while $\mathrm{Li}$ et $\mathrm{al}^{(2)}$ and Tai et $\mathrm{al}^{(3)}$ reported the early Singapore experience with colorectal endoscopic submucosal dissection (ESD). The aim of IEE as an adjunct to standard white light endoscopy is to improve endoscopic detection, characterisation and diagnosis of mucosal lesions. This would facilitate subsequent management strategies, including endoscopic resection or surgery. It is thus appropriate to take the opportunity to briefly examine the crucial issue of optimising endoscopic management of early gastrointestinal (GI) neoplasia. This would encompass preprocedural preparation, intraprocedural diagnosis, endoscopic treatment and post-resection follow-up options guided by histopathological findings.

Endoscopy is the gold standard test for examining GI mucosa. However, to improve diagnostic yield, the mucosal surface must be clean and not obscured by mucus, fluids or other solid debris. Hence, adequate fasting, appropriate use of mucolytics and anti-foaming agents (for upper endoscopy), and good bowel preparation (for colonoscopy) are crucial. Quality endoscopic examinations are characterised by careful, deliberate and meticulous techniques. Surrogate markers of a quality examination include diagnostic procedure time, cleanliness of mucosal surface, completeness of examination, quality of captured endoscopic images and adenoma detection rates. IEE techniques are an important adjunct to white light endoscopy to improve lesion detection, characterisation and diagnosis. This may be achieved using dye spray chromoendoscopy such as the absorptive dye, Lugol's iodine, for detection of dysplastic oesophageal squamous lesions and the contrast dye, indigo carmine, which is used to highlight mildly elevated or mildly depressed mucosal lesions in the stomach and colon - or by equipment-based optical techniques. The latter techniques include NBI and blue light imaging, which focus on mucosal surface details and can be combined with optical magnification to characterise a detected lesion to determine whether it is neoplastic; if the lesion is neoplastic, the likelihood of deep submucosal involvement and feasibility of curative endoscopic resection are examined.

Endoscopic classification systems based on these narrow-bandwidth imaging features have been established for the oesophagus, stomach and colon to guide treatment decisions. These include the intrapapillary capillary loop classification system for oesophageal squamous neoplasia, ${ }^{(4)}$ the BING (Barrett's International NBI Group) classification system for Barrett's oesophagus, ${ }^{(5)}$ the VS (vessel plus surface) classification system for early gastric cancer $^{(6)}$ and the NBI and JNET (Japan NBI Expert Team) classification systems for colorectal neoplasia. ${ }^{(7)}$ It is important for an endoscopist to correctly describe the morphology of a detected lesion using the Paris morphological classification system, followed by an assessment of the likelihood of dysplasia or malignancy, and the extent and depth of invasion, using the appropriate endoscopic classification system based on the organ involved. Consensus guidelines of standards for diagnostic upper and lower GI endoscopy have been published, and all endoscopists should be mindful of the requirements for a quality examination. ${ }^{(8,9)}$

GI neoplasia, including early cancer with no or minimal risk of metastases, should undergo curative endoscopic resection. This curative treatment option is minimally invasive and organ preserving. En bloc resection, when feasible, is preferred so that a proper histopathological assessment can be performed of clearance of resection margins and endoscopic curative criteria. Pedunculated polyps can be easily captured by snare and resected. In the case of flat mucosal lesions, advanced techniques such as endoscopic mucosal resection (EMR) and ESD are needed. EMR is not able to ensure en bloc resection with adequate margins for lesions larger than $15 \mathrm{~mm}$ in the upper $\mathrm{Gl}$ tract and larger than $20 \mathrm{~mm}$ in the lower Gl tract. In this context, if advanced lesions such as high-grade dysplasia or early cancer are suspected based on imaging or from biopsies, ESD should be performed. Piecemeal EMR is an option for colonic low-grade dysplasia but is associated with a higher rate of local recurrence and the need for repeat procedures. For large lesions, there is a distinct possibility of a lesion being upstaged after resection, and if the histology reveals early cancer after piecemeal EMR, there may be uncertainty about whether endoscopic cure has been achieved.

Histopathological assessment of the resected specimen is the final arbiter of whether endoscopic cure has been achieved. It will guide the subsequent management decision of surveillance or salvage surgery. Surgical histopathological correlations have established risk prediction criteria for nodal metastases in early GI cancer. ${ }^{(10,11)}$ However, what matters to the patient is the morbidity of the procedure, recovery time and disease-free recurrence. 


\section{REFERENCES}

1. Koay DSC, Ghumman A, Pu LZCT, Singh R. Narrow-band imaging with wate immersion technique: a case-finding, cost-effective approach to villous atrophy. Singapore Med J 2019; 60:522-5.

2. Li JW, Ang TL, Wong LM, et al. Endoscopic submucosal dissection of colorecta neoplasms: an audit of its safety and efficacy in a single tertiary centre in Singapore. Singapore Med J 2019; 60:526-31.

3. Tai YS, Clement LK, Chia CLK, Tan KY. Endoscopic submucosal dissection of colonic lesions: first 50 cases at a local institution. Singapore Med J 2019; 60:508-11.

4. Inoue $\mathrm{H}$, Kaga $\mathrm{M}$, Ikeda $\mathrm{H}$, et al. Magnification endoscopy in esophageal squamous cell carcinoma: a review of the intrapapillary capillary loop classification. Ann Gastroenterol 2015; 28:41-48.

5. Sharma P, Bergman JJ, Goda K, et al. Development and validation of a classification system to identify high-grade dysplasia and esophagea adenocarcinoma in Barrett's esophagus using narrow-band imaging. Gastroenterology 2016; 150:591-8.
6. Yao K, Anagnostopoulos GK, Ragunath K. Magnifying endoscopy for diagnosing and delineating early gastric cancer. Endoscopy 2009; 41:462-7.

7. Sano $\mathrm{Y}$, Tanaka $\mathrm{S}$, Kudo SE, et al. Narrow-band imaging (NBI) magnifying endoscopic classification of colorectal tumors proposed by the Japan NBI Expert Team. Dig Endosc 2016; 28:526-33.

8. Chiu PWY, Uedo N, Singh R, et al. An Asian consensus on standards of diagnostic upper endoscopy for neoplasia. Gut 2019; 68:186-97.

9. Sano Y, Chiu HM, Li XB, et al. Standards of diagnostic colonoscopy for earlystage neoplasia: recommendations by an Asian private group. Dig Endosc 2019; 31:227-44.

10. Ono H, Yao K, Fujishiro M, et al. Guidelines for endoscopic submucosal dissection and endoscopic mucosal resection for early gastric cancer. Dig Endosc 2016; 28:3-15.

11. Watanabe T, Muro K, Ajioka Y, et al. Japanese Society for Cancer of the Colon and Rectum (JSCCR) guidelines 2016 for the treatment of colorectal cancer. Int J Clin Oncol 2018; 23:1-34. 